\title{
VICO Y YO
}

\section{Alfonso García Marqués (Universidad de Murcia)}

RESUMEN: Considero que el pensamiento de Vico es un gigantesco esfuerzo para explicar los procesos colectivos de humanización, mostrando los principios que constituyen lo humano, a partir de los cuales se puede elaborar un ius naturale gentium que oriente la praxis humana.

Palabras Clave: Vico, $350^{\circ}$ Aniversario, mundo humano, historia, derecho natural, A. García Marqués.

\section{Vico and myself}

ABSTRACT: I consider that Vico's thought is a gigantic effort to explain the collective processes of humanization, showing the principles that constitute humanity, from which a ius naturale gentium can be elaborated in order to guide human praxis.

KEYwORDS: Vico, $350^{\text {th }}$ Anniversary, human world, history, natural law, A. García Marqués.

\section{Vico ed io}

RiASSUNTO: Credo che il pensiero di Vico sia un gigantesco sforzo volto a spiegare i processi collettivi di umanizzazione mostrando i principi che costituiscono l'umano, a partire dai quali è possibile elaborare un ius naturale gentium che orienti la prassi umana.

PAROle ChiAVE: Vico, $350^{\circ}$ Anniversario, mondo umano, storia, diritto naturale, A. García Marqués.

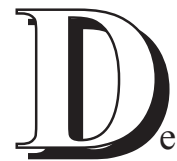

todos es sabido la absoluta ausencia de Vico en los planes de estudio de filosofía en las universidades españolas. Yo padecí esa situación: cuando concluí mis estudios en 1976, nunca había oído hablar de este autor. Por eso, mi primer contacto con Vico fue gracias a un estudiante italiano que, en 1984, me pidió dirigirle una tesina sobre la hermenéutica de la historia en Vico. Creo que, en todos los años de mi dedicación a la docencia, fue ese el momento más novedoso, pues los demás temas estudiados o autores investigados tienen su raíz en los estudios universitarios o incluso en el bachillerato, mientras que el descubrimiento de Vico fue para mí una total novedad. Desde entonces mi contacto con el genial napolitano no ha sido exclusivo, pero sí continuo.

Este artículo responde a una invitación expresa por parte de la Dirección de la Revista para este volumen especial por el $350^{\circ}$ Aniversario del nacimiento de G. Vico, habiendo superado los criterios de valoración y del proceso de aceptación. 
En mi primera aproximación, la obra de Vico se me presentó, en su conjunto, como una especie de enciclopedia barroca, donde ciertamente podíamos encontrar todos los saberes teoréticos y prácticos, pero expuestos de una manera artificiosa y complicada. La dificultad de entender el sentido de la filosofía de Vico me impelió a la lectura de la literatura interpretativa; sin embargo, esto fue más una complicación que una ayuda, pues lo que comprobé es que la interpretación de Vico está ciertamente lejos de ser homogénea. En mis lecturas de la bibliografía secundaria se me presentó la filosofía viquiana como un positivismo, un empirismo o un utilitarismo; como un platonismo, un agustinismo o, incluso, como una filosofía cristiana, sea tomista o escotista; como un idealismo ante litteram; como una filosofía transcendental o como un transcendentalismo lingüístico; como un marxismo o como una defensa de la vieja cultura hispano-italiana frente a las tendencias afrancesadas; como el origen de las ciencias histórico-sociales, de la antropología y de las ciencias humanas en general; e incluso algunos presentaban a Vico como un autor sin relevancia especulativa.

En medio de esa cacofonía, me pareció especialmente acertada la interpretación de tipo gnoseológico y transcendental defendida por Stephan Otto, profesor en Múnich, con quien he tenido el gusto de conversar más de una vez. El interés por esa interpretación me llevó a realizar una estancia en Múnich de dos meses, en el segundo semestre del curso 1987-1988. A partir de ese año comencé a impartir materias de doctorado sobre la gnoseología viquiana, aproveché diversos congresos (Málaga, Palermo, Messini...) para hablar sobre el sentido de la filosofía de Vico y sobre interpretaciones de la Scienza nuova, e inicié mis publicaciones sobre este autor.

No un giro, pero sí una nueva comprensión más profunda de la obra de Vico fue el descubrimiento, en su Autobiografía, de la interpretación que allí ofrece de su propia trayectoria intelectual. No duda en mostrar abiertamente su intención de fondo y la continuidad de su obra:

«Desde el tiempo de la primera oración que he reseñado, y tanto en aquélla como en todas las siguientes, pero especialmente en la última, se ve abiertamente que yo agitaba en mi ánimo un argumento nuevo y grande: hallar un principio que uniese todo el saber humano y divino» (Autobiografia, 24).

Creo que la unidad e intención de la obra viquiana no puede estar expresada con más claridad: la búsqueda de la unidad del saber, lograda a través del hallazgo de un principio unificante. Y esa fue la idea central que guió la elaboración de mi libro Vico. Unidad y principio del saber, publicado en el 1995, donde intento hacer una exposición sistemática de la filosofía de Vico, tal como aparece en su Scienza nuova, pero asumiendo las diversas elaboraciones anteriores. 
Desde esa perspectiva, pienso que se pueden describir las principales obras de Vico como reiteradas concreciones de su intento por construir una filosofía unitaria que abarcase todo el saber de su época, y superase las fuertes limitaciones de la filosofía imperante, es decir, del cartesianismo, aunque también del empirismo y demás reductivismos. De este modo, creo que, en función de sus principios filosóficos, Vico pudo dar razón de las ciencias de la naturaleza que ya habían sido elaboradas (físicas antigua y moderna) y de los conocimientos del mundo humano (el derecho, la economía, política, etc.), pero lo principal, en mi opinión, es que su pensamiento es una nueva fundamentación y reconstrucción del mundo humano en todas sus facetas, incluida una nueva concepción del hombre, para lo que atiende especialmente a sus dimensiones sociales e históricas.

Para mí este descubrimiento de que el pensamiento de Vico ofrecía una nueva concepción del ser humano y de sus actividades teóricas y prácticas fue decisivo. Ciertamente, he dedicado buena parte de mi investigación a Aristóteles, en el convencimiento de que su filosofía proporciona las bases ontológicas y gnoseológicas para la comprensión de la physis, sea natural sea humana, en sus aspectos principalmente individuales, pues para Aristóteles el eterno problema de qué es ente equivale a qué es substancia (Met. Z 2). Por eso, considero al Estagirita como uno de mis dos autores. Pero el otro autor es Vico, pues me parece que su pensamiento es decisivo para entender los aspectos colectivos de la humanidad y, en consecuencia, sostengo que el tema de la Scienza nuova es precisamente la naturaleza común de las naciones: la comprensión de la construcción del mundo humano como un todo a través de sus procesos colectivos históricos. El sujeto no es solo el individuo, sino también y principalmente las naciones.

Considero que el elemento central para la interpretación de Vico es el verum esse factum (lo verdadero es lo hecho), reinterpretado en la Scienza nuova con la genial teoría de las modificaciones de la mente (la poética y la reflexiva). Ese es el principio que explica unitariamente todo el saber humano y divino. Vico subraya explícitamente que el descubrimiento de los diversos tipos de mente -las modificaciones- y cómo funcionan «es la llave maestra de esta Ciencia» (SN44, §34); y que las dificultades que ha tenido para encontrarlas «nos han costado la búsqueda obstinada de casi toda nuestra vida literaria» (ibíd.).

La aplicación de ese principio combinado con las modificaciones tiene, en mi opinión, un triple rendimiento.

$\left.1^{\circ}\right)$ La comprensión de la génesis interna de cada una de las obras de Vico a lo largo de su curso intelectual, a partir del grado de madurez que el verum factum iba alcanzando en su mente. Encontramos los primeros tanteos en las Orationes y el De nostri temporis studiorum ratione, que, aunque se sitúan en el ámbito del humanismo, explicitando temas como la educación de la juventud, el cultivo de las artes y ciencias humanas (retórica, tópica, moral, política...) en polémica con el car- 
tesianismo, el argumento unitario de fondo es la sabiduría. Vico de modo casi implícito ya estaba dando los primeros pasos en la búsqueda de la unidad de los saberes a partir de un principio.

Su primera gran obra filosófica -el De antiquissima Italorum sapientia- es un intento formal de sistematización y fundamentación de todo el saber humano, realizado principalmente a través del descubrimiento de su famoso principio verum esse factum. En este sentido, el De antiquissima puede considerarse como una teoría sobre los límites y alcance del conocimiento, que mantiene un equilibrio entre el escepticismo y el dogmatismo.

Sin embargo, en esa última obra Vico no logra culminar su tarea: la fundamentación de las ciencias humanas. Se ve claramente porque, en ella, Vico sostiene que el conocimiento más perfecto es el matemático y que el conocimiento de lo humano, en concreto de la moral, es totalmente incierto, puesto que nuestras acciones proceden del arbitrio humano, que es máximamente indeterminado. Todavía hemos de ver dos intentos sucesivos de fundación del saber-De uno universi iuris principio et fine uno y De constantia iurisprudentis-, antes de que Vico logre hacerse cargo de todo el alcance especulativo de su principio, y obtenga sus consecuencias principales, tal como aparece en la primera edición de su nueva Ciencia, la Scienza nuova prima, cuya versión definitiva es la Scienza nuova seconda. De este modo, el napolitano pudo considerar finalmente que había logrado su propósito:

«En esta obra se encuentra, por fin, totalmente desarrollado aquel principio, que confusamente y no con toda distinción había concebido en mis obras precedentes» (Autobiografia, 35).

Por fin, Vico ha conseguido librarse totalmente de la idea de que el hombre es una mente (cartesiana o platónica), que sin limitaciones conoce haciendo, al modo de la mente divina. En la Scienza nuova la mente humana está vinculada a un cuerpo, conoce inicialmente de modo sensible-imaginativo y, posteriormente, de modo intelectivo. Se trata de un "despliegue" de la mente en dos momentos: la mente poética y la mente reflexiva, que es la «ragione spiegata» $(S N 44, \S 1.045)$.

En consecuencia, según la concepción "confusa" del verum factum, en el De antiquissima tenemos una ciencia plenamente constructiva (las matemáticas) y otra ciencia parcialmente constructiva (la física experimental), capaz esta de hacer parcialmente las realidades naturales. En la Scienza nuova, según el doble momento del verum factum, ahora «tutto spiegato», además de esas dos ciencias, tenemos una nueva Ciencia, apta para explicar el origen real -histórico, res gestae- de las naciones y de todas las cosas humanas y, además, capaz de justificar suficientemente nuestro conocimiento sobre todas esas realidades. 
$2^{\circ}$ ) El segundo rendimiento del verum factum viquiano es la explicación teórica del nacimiento de lo humano colectivo. Yo subrayaría que Vico es el filósofo de la historia, pero no de la historia de los reyes y de las guerras, sino de las naciones como auténticos sujetos. Vico descubre que, además de las realizaciones singulares, contingentes, arbitrarias de cada individuo, hay un mundo humano común a todos: el mundo civil. Ese mundo se articula en naciones, que es lo que se construye colectivamente, fruto de una mente poética, y que luego puede ser reconstruido científicamente por la mente reflexiva. Por eso, el objeto de la ciencia viquiana -lo que se construye realmente y se reconstruye cognitivamente- es la naturaleza común de las naciones.

La explicación teórica del mundo humano se hace a partir de los tres principios que generan la humanización y permiten su comprensión; o sea, son simultáneamente los principios reales y los principios de la Scienza nuova: religiones, matrimonios y sepulturas. Además, desde un punto de vista metafísico -cómo son las cosas in re-, el establecimiento de los principios conduce a Vico a la conclusión de que los hombres no solo han actuado de un cierto modo porque admitían esos principios, sino que las cosas realmente son así. Es decir, no solo la mente poética crea ese mundo, sino que la mente reflexiva -el saber riguroso, sc. la filosofíarevalida que las cosas son así. Dicho de otro modo, hay una perfecta coordinación entre costumbres, pensamiento y realidad: todos los pueblos celebran matrimonios solemnes, entierran a sus muertos y tienen religiones, en el convencimiento de que podemos moderar las pasiones, de que no perecemos totalmente y de que hay una divinidad providente; $y$, como las cosas fuera de su estado ni se mantienen ni perduran, esas costumbres y creencias implican que realmente hay libertad, alma inmortal y Dios providente, lo cual es demostrado por la razón reflexiva, que es lo que Vico hace en su Scienza nuova.

$3^{\circ}$ ) El tercer rendimiento del verum factum son los aspectos prácticos de la Scienza nueva, me refiero al ius naturale gentium viquiano, a la Scienza nuova como arte diagnóstica y a la importantísima teoría de la akmé. En mi dedicación a estos temas fue decisiva la invitación que me hizo el profesor José M. Sevilla a presentar una ponencia en el Congreso Internacional sobre Vico Pensar para el nuevo siglo. Giambattista Vico y la cultura europea (Sevilla 1999) y la invitación del profesor Fabrizio Lomonaco a hablar en el V Premio Filosofico G. Vico (Nápoles 2016).

La idea de que hay un derecho natural de gentes es una idea de los humanistas antiguos y modernos, pero considero que fue desarrollada genialmente por Vico, al introducirlo en su sistema de las diversas etapas ternarias de la humanidad (edad de los dioses, de los héroes y de los hombres). De este modo, Vico consigue elaborar un nuevo sistema de derecho natural, que mantiene un equilibrio entre la idea de una ley natural eterna, inmutable y abstracta, y un derecho totalmente circunstancial, meramente humano, sometido al arbitrio - a veces irracional- de los 
gobernantes. Vico era consciente de la importancia de su ius naturale gentium, y lo consideraba el principal corolario de su Scienza nuova (Vici vindiciae, III, viii).

Hoy intentamos fundamentar la acción humana a través de los derechos humanos, de los valores, de los modelos, de los códigos deontológicos, de los sentimientos, de la conciencia, de los ideales, de la voluntad de Dios..., pero yo personalmente pienso que el único fundamento posible, la única guía realmente válida es el ius naturale gentium tal como lo concibió Vico, y es la idea que me ha guiado en la elaboración de un manual de ética y filosofía política (Civis bonus), que publiqué en 2010.

Esa validez del ius viquiano hace que su Scienza nuova sea un arte diagnóstica. Un arte que nos permite conocer los signos indudables del estado de las naciones, en función de los tres principios de la Scienza nuova. Se trata de hacer un diagnóstico para saber si una nación marcha hacia su akmé o hacia su decadencia:

«Puesto que sus tres principios son la providencia divina, la moderación de las pasiones con los matrimonios y la inmortalidad de las almas humanas con las sepulturas; [...] y en estos principios concuerda la sabiduría vulgar de todos los legisladores y la sabiduría reflexiva de los más reputados filósofos: éstos deben ser los confines de la humana razón. Y quien se quiera ir fuera de ellos, mire si no se va fuera de toda humanidad» $(S N 44, \S 360)$.

Quisiera hacer, para concluir, una reflexión sobre la influencia del pensamiento de Vico y su proyección en el futuro. Como es sabido, la filosofía de Vico no fue precisamente la que triunfó en Europa, sino más bien el racionalismo, que, transformado en pensamiento ilustrado, plasmó la conciencia europea hasta nuestros días, en que la posmodernidad parece haber sido la liquidación definitiva de la Ilustración. En este sentido, la filosofía de Vico tiene aún mucho que decirnos a los occidentales de inicios del siglo XXI: el pensamiento viquiano fue un intento, distinto del racionalismo y, por tanto, de la Ilustración, por fundar una civilización. Por esto mismo, la filosofía de Vico se ha revalorizado constantemente a lo largo del siglo XX. No pocos pensadores se remiten a ella para obtener nuevos modos de enfocar las cuestiones que nos preocupan, y declaran abiertamente que Vico es el antecesor de no pocas actuales disciplinas, tales como la filología, la sociología, la filosofía de la historia y, en general, las ciencias del espíritu.

Quiero poner un ejemplo de cómo me ha ayudado Vico a entender la historia. Para mí son muy importantes los corsi y ricorsi viquianos, puesto que son totalmente reales y no solo una ingeniosa ficción barroca. No solo la historia de una nación concreta, sino la de Europa o la de Occidente (si queremos contar también sus proyecciones en América) hemos de pensarla como corsi e ricorsi. Creo que la 
división de nuestra historia en las cuatro edades (antigua, media...) no aporta suficiente comprensión ni claridad. Europa ha tenido dos corsi viquianos. Hablando en fechas simbólicas, el primero va desde el 753 a.C., con la fundación de Roma y composición de la Ilíada y la Odisea, hasta el 751 p.C., con la subida al poder de los carolingios, la ruptura entre Roma y Constantinopla y la expansión del Islam. A partir de entonces comienza el segundo corso de Europa, el nuestro: se inicia la formación de los reinos medievales, que darán lugar a las naciones modernas europeas que somos nosotros como unidades históricas; se formarán las entidades más características de nuestro mundo: la universidades medievales, que darán lugar a las modernas; y así en todos los órdenes.

Es más, si atendemos a la diagnóstica viquiana, ya sabemos que hemos entrado en el fin de ciclo: no estamos en la posmodernidad sino en la tardomodernidad o Modernidad tardía, caracterizada por la «barbarie de la reflexión» (SN44, § 1.106), o sea, la filosofía de la sospecha y crítica a todos los valores y, por la posverdad, es decir, cuando los «necios doctos se dedican a calumniar la verdad» (§ 1.102). Todo esto significa que las estructuras, instituciones, mentalidad y tipos de hombre construidos en este segundo corso a partir de los tres principios viquianos de humanización están siendo sistemáticamente deconstruidos: la religión mediante la secularización, la inmortalidad mediante los reductivismos e identificación del hombre con el animal, y los matrimonios mediante el individualismo y las diversas formas de unidades familiares.

Pienso que ese sería el juicio de Vico sobre nuestro tiempo, que podrá parecer negativo, pero en el fondo anuncia el inicio de un tercer corso, que con la guía de Vico, podrá estar lleno de esplendor, pues a partir de la akmé «podemos aprender los procedimientos para que la humanidad de una nación, surgiendo, pueda llegar al estado perfecto; $y$, habiendo decaído, pueda de nuevo alcanzar la plenitud»» $(S N 25, \S 11)$.

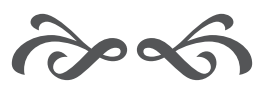


<smiles>[As]</smiles> 